\title{
Post-coital intra-cerebral venous hemorrhage in a 78-year-old man with jugular valve incompetence: a case report
}

Beatrice Albano ${ }^{1}$, Carlo Gandolfo ${ }^{1}$, Massimo Del Sette ${ }^{2^{*}}$

\begin{abstract}
Introduction: Spontaneous intra-cerebral hemorrhage can occur in patients with venous disease due to obstructed venous outflow.
\end{abstract}

Case presentation: We report the case of a 78-year-old Caucasian man with jugular valve incompetence who experienced an intra-cerebral temporo-occipital hemorrhage following sexual intercourse. He had no other risk factors for an intra-cerebral hemorrhage.

Conclusions: To the best of our knowledge, this is the first case of intra-cerebral hemorrhage due to jugular valve incompetence in association with the physical exertion associated with sexual intercourse.

\section{Introduction}

Non-traumatic spontaneous intra-cerebral hemorrhage is usually due to hypertensive arteriolosclerosis or to amyloid angiopathy, which account for 78 to $88 \%$ of primary hemorrhages, whereas secondary intra-cerebral hemorrhage is normally associated with arteriovenous malformation, aneurysm, cavernous angioma, neoplasm, coagulopathy or the misuse of drugs [1].

Ganglionic hemorrhages are probably of hypertensive origin, while lobar hemorrhages are frequently due to amyloid angiopathy or vascular malformations [2].

Some authors have reported the occurrence of intracerebral hemorrhages that have been caused by venous diseases. These are usually located in the white matter at the border zone between deep and superficial venous systems where collaterals are poor. Venous intracerebral hemorrhages are associated with impaired venous hemodynamics, as in the case of cerebral venous thrombosis, compression of the superior cava vein or right cardiac failure [3]. Moreover, the occurrence of petechial hemorrhages during cerebral venous thrombosis is a frequent finding on computed tomography (CT) or magnetic resonance imaging (MRI) scans $[4,5]$.

\footnotetext{
* Correspondence: massimo.delsette@asl5.liguria.it
}

${ }^{2} \mathrm{~S}$. Andrea Hospital. La Spezia, Italy

(c) 2010 Albano et al; licensee BioMed Central Ltd. This is an Open Access article distributed under the terms of the Creative Commons Attribution License (http://creativecommons.org/licenses/by/2.0), which permits unrestricted use, distribution, and reproduction in any medium, provided the original work is properly cited.
We report the case of a patient with bilateral severe jugular valve incompetence in whom a cerebral hemorrhage occurred soon after the physical effort of sexual intercourse.

\section{Case presentation}

A 78-year-old Caucasian man was referred to our stroke unit because of the sudden onset of a headache associated with speech and visual disturbances during early morning sexual intercourse. He had been lying in a supine position with his head hanging off the bed in a slightly downwards position. The patient was brought to the hospital few hours later. On admission, neurological examination showed a right hemianopia with alexia. His systolic blood pressure was $115 \mathrm{mmHg}$ and the diastolic pressure was $60 \mathrm{mmHg}$.

A thorough review of familial and personal clinical histories suggested no other possible cause for this condition. In particular, there were no signs of arterial hypertension or hematological disorders and our patient was not taking anti-coagulants or anti-platelet drugs. He had not experienced any head trauma and had no other risk factors for cerebrovascular disease. He had also not taken sildenafil citrate or any other cyclic guanosine monophosphate (cGMP) inhibitors.

A cerebral CT scan showed a small left cortical temporo-occipital hemorrhage with mild mass effect and 


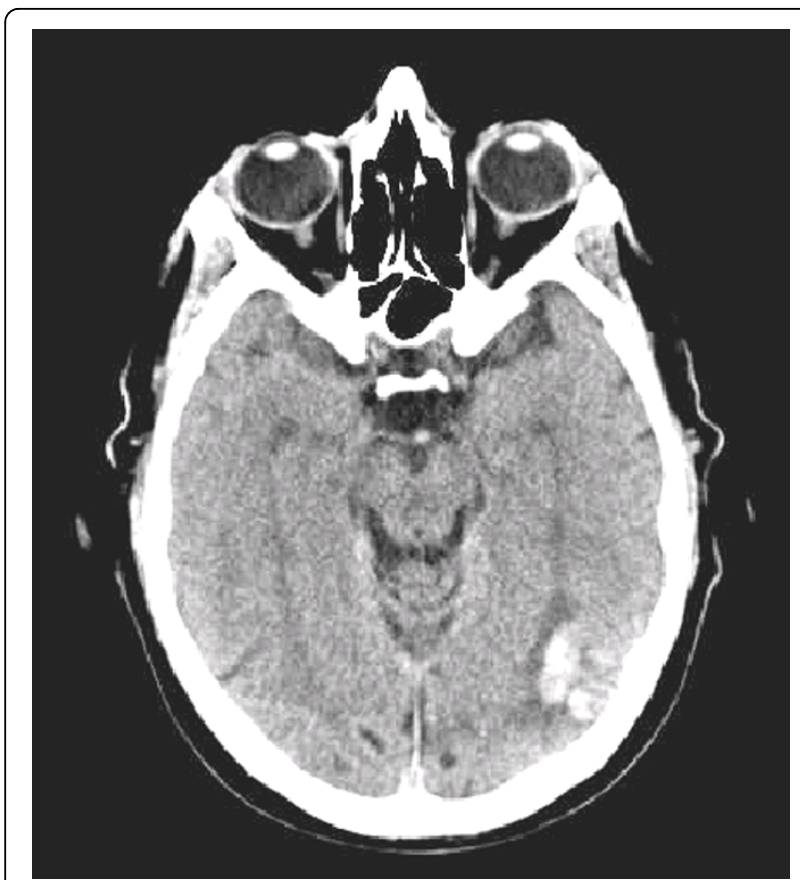

Figure 1 Cerebral computed tomography scan showing a small left cortical temporo-occipital hemorrhage, with mild mass effect and hypodense halo

hypodense halo (Figure 1). A carotid and vertebral duplex scan was normal, as was an arterial trans-cranial Doppler. Neuropsychological testing and a neuropsychiatric interview showed no cognitive impairment (Mini-Mental State Examination (MMSE) was 29 out of 30). Routine blood tests, including a platelet count and the plasma level of coagulation factors gave results within normal ranges. A peri-umbilical biopsy for systemic amyloidosis was normal. A cerebral MRI was not carried out because of the presence of abdominal vascular clips. Therefore, a contrastenhanced CT scan and a traditional digital subtraction angiography (DSA) were performed the following day to rule out the possibility of cerebral venous thrombosis or arteriovenous malformations. These tests provided no evidence of venous thrombosis or vascular malformations, whereas an air contrast ultrasound venography (ACUV) of the jugular veins showed a severe bilateral jugular valve incompetence, with a huge reflow to the brain during a Valsalva maneuver [6,7].

Our patient was discharged a week after presentation, with mild left hemianopia and alexia. The control CT scan showed a partial regression of the cerebral hemorrhage. He was advised to be careful during physical activity and to frequently measure his blood pressure.

\section{Discussion}

We present a case of post-coital intra-cerebral venous hemorrhage in a patient with jugular valve incompetence.
We suggest that the physical effort during sexual intercourse (during which our patient's head was hanging off the bed in a slightly downwards position) could have caused the intra-cerebral hemorrhage as there was a close temporal relationship between the physical effort and neurological symptoms.

Post-coital intra-cerebral hemorrhage has been previously described in association with hypertension, the presence of vascular malformations, or the use of sildenafil citrate [8-10].

Although our patient was not hypertensive, the possible contribution of a hypertensive peak during the physical effort cannot be excluded, although in cases described in the literature, such hemorrhages are situated in the deep gray matter. In fact, above the circle of Willis, in the deep gray matter of the basal ganglia and thalamus, arterioles are closer to the direct pulse pressure of the large supplying arteries and there are no branches prior to the arterioles that allow stepwise reduction in pulse pressure $[11,12]$. In our patient, the lobar cortical hemorrhage was more probably related to local hemodynamic impairment. Lobar hemorrhages are usually due to amyloid angiopathy, vascular malformations, neoplasm, coagulopathies, or the misuse of drugs.

Our patient had no cognitive impairment, no systemic amyloidosis, no neoplasms, vascular malformations or history of drug misuse, so all these possible causes could be excluded.

In reported cases of intra-cerebral hemorrhages due to cerebral venous thrombosis, the pathogenetic mechanism is thought to be the presence of an obstacle to venous outflow represented by a venous thrombus. In our patient, the obstruction to venous flow was caused by the Valsalva maneuver together with the incompetence of the jugular valves, which was 'severe' according to the published classification criteria [13]. The bilateral pathology of the jugular veins did not allow good collateral outflow pathways, and physical effort together with forced expiration are known to be causes of raised cerebral venous pressure $[14,15]$. Jugular valve incompetence has been reported in association with transient global amnesia and transient monocular blindness $[13,16,17]$, but, to the best of our knowledge, it has not been associated with increased risk of post-coital effort intra-cerebral hemorrhage.

As our patient was not hypertensive, not under any treatment and not affected by any coagulation disorder, and a DSA showed no vascular malformation, we argue that the severe jugular valve incompetence, together with the head-down position, physical effort and forced expiration could have facilitated venous congestion and secondarily, intra-cerebral hemorrhage [14,15].

To the best of our knowledge, this is the first reported case of intra-cerebral hemorrhage during sexual intercourse in a subject with jugular valve incompetence. 


\section{Consent}

Written informed consent was obtained from the patient for publication of this case report and any accompanying images. A copy of the written consent is available for review by the Editor-in-Chief of this journal.

\section{Abbreviations}

ACUV: air contrast ultrasound venography; cGMP: cyclic guanosine monophosphate; CT: computer tomography; DSA: digital subtraction angiography; MMSE: Mini-mental State Examination; MRI: magnetic resonance imaging.

\section{Author details}

${ }^{1}$ Department of Neuroscience, Ophthalmology and Genetic, University of Genova, Italy, Via De Toni 5, 16132 Genova, Italy. ${ }^{2}$ S. Andrea Hospital. La Spezia, Italy.

\section{Authors' contributions}

BA analyzed and interpreted the patient's data and collected the literature. CG contributed to writing the manuscript. MDS performed the ultrasound and interpreted the pathophysiology of the cerebral hemorrhage. All authors read and approved the final manuscript.

\section{Competing interests}

The authors declare that they have no competing interests.

Received: 5 January 2009 Accepted: 26 July 2010

Published: 26 July 2010

\section{References}

1. Foulkes MA, Wolf PA, Price TR, Mohr JP, Hier DB: The Stroke Data Bank: designs, methods, and baseline characteristics. Stroke 1988, 19(5):547-554.

2. Auer RN, Sutherland GR: Primary intracerebral haemorrhage: pathophysiology. Can J Neurol Sci 2005, 32(Suppl 2):S3-S12.

3. Vuia O, Alexianu M: Veinous insufficiency of the brain: cerebral softening and hemorrhage of veinous origin. J Neurol Sci 1968, 7(3):495-509.

4. Shintaku M, Yasui N: Chronic superior sagittal sinus thrombosis with phlebosclerotic changes of the subarachnoid and intracerebral veins. Neuropathology 2006, 26(4):323-328.

5. Girot M, Ferro JM, Canhão P, Stam J, Bousser MG, Barinagarrementeria F, Leys D, ISCVT Investigators: Predictors of outcome in patients with cerebral venous thrombosis and intracerebral hemorrhage. Stroke 2007, 38(2):337-342.

6. Ratanakorn $\mathrm{D}$, Tesh PE, Tegeler $\mathrm{CH}$ : A new dynamic method for detection of internal jugular valve incompetence using air contrast ultrasonography. J Neuroimaging 1999, 9(1):10-14.

7. Akkawi NM, Agosti C, Borroni B, Rozzini L, Magoni M, Vignolo LA, Padovani A: Jugular valve incompetence: a study using air contrast ultrasonography on a general population. J Ultrasound Med 2002, 21:747-751.

8. Finelli PF: Coital cerebral hemorrhage. Neurology 1993, 43:2683-2685.

9. Monastero R, Pipia C, Camarda LKC, Camarda R: Intracerebral haemorrhage associated with sildanafil citrate. J Neurol 2001, 248:141-142.

10. Buxton N, Flannery T, Wild D, Bassi S: Sildenafil (Viagra)-induced spontaneous intracerebral haemorrhage. Br J Neurosurg 2001, 15(4):347-349.

11. Jackson CA, Suldow CLM: Is hypertension a more frequent risk factor for deep than for lobar supratentorial intracerebral haemorrhage? J Neurol Neurosurg Psychiatry 2006, 77:1244-1252.

12. Juvela S, Hillbom M, Palomaki H: Risk factors for spontaneous intracerebal haemorrhage. Stroke 1995, 26(9):1558-1564.

13. Akkawi NM, Agosti C, Anzola GP, Borroni B, Magoni M, Pezzini A, Rozzini L, Vignolo LA, Padovani A: Transient global amnesia: a clinical and sonographic study. Eur Neurol 2003, 49:67-71.

14. Schaller B, Graf R: Cerebral venous infarction: the pathophysiological concept. Cerebrovasc Dis 2004, 18:179-188.
15. Schaller B: Physiology of cerebral venous blood flow: from experimental data in animals to normal function in humans. Brain Res Rev 2004, 46(3):243-246.

16. Schreiber SJ, Doepp F, Klingebiel R, Valdueza JM: Internal jugular vein valve incompetence and intracranial venous anatomy in transient global amnesia. J Neurol Neurosurg Psychiatry 2005, 76:509-513.

17. Hsu HY, Chao AC, Chen YY, Yang FY, Chung CP, Sheng WY, Yen MY, $\mathrm{Hu} \mathrm{HH}$ : Reflux of jugular and retrobulbar venous flow in transient monocular blindness. Ann Neurol 2008, 63:247-253.

doi:10.1186/1752-1947-4-225

Cite this article as: Albano et al: Post-coital intra-cerebral venous hemorrhage in a 78-year-old man with jugular valve incompetence: a case report. Journal of Medical Case Reports 2010 4:225.

\section{Submit your next manuscript to BioMed Central and take full advantage of:}

- Convenient online submission

- Thorough peer review

- No space constraints or color figure charges

- Immediate publication on acceptance

- Inclusion in PubMed, CAS, Scopus and Google Scholar

- Research which is freely available for redistribution

Submit your manuscript at www.biomedcentral.com/submit 